TITLE:

\title{
Application of compact microwave ion source to low temperature growth of transition metal nitride thin films for vacuum microelectronics devices
}

\author{
$\operatorname{AUTHOR}(\mathrm{S}):$ \\ Gotoh, Y; Tsuji, H; Ishikawa, J
}

\section{CITATION:}

Gotoh, Y ... [et al]. Application of compact microwave ion source to low temperature growth of transition metal nitride thin films for vacuum microelectronics devices. REVIEW OF SCIENTIFIC INSTRUMENTS 2000, 71(2): 1002-1005

ISSUE DATE:

2000-02

URL:

http://hdl.handle.net/2433/39801

\section{RIGHT:}

Copyright 2000 American Institute of Physics. This article may be downloaded for personal use only. Any other use requires prior permission of the author and the American Institute of Physics. 


\title{
Application of compact microwave ion source to low temperature growth of transition metal nitride thin films for vacuum microelectronics devices
}

\author{
Y. Gotoh, ${ }^{\text {a) }}$ H. Tsuji, and J. Ishikawa \\ Department of Electronic Science and Engineering, Kyoto University, Sakyo-ku, Kyoto 606-8501, Japan
}

(Presented on 7 September 1999)

\begin{abstract}
A compact microwave ion source was applied to the low temperature growth of transition metal nitride thin films for the cathode of vacuum microelectronics devices. An ion beam assisted deposition system consisted of a compact microwave ion source and an electron beam evaporator was developed. Depositions of zirconium nitride and niobium nitride thin films were performed and the film properties were investigated. As a result, it was found that polycrystalline films of zirconium nitride and niobium nitride were prepared at the substrate temperature as low as $500{ }^{\circ} \mathrm{C}$, which was almost $200^{\circ} \mathrm{C}$ lower than the results shown in the literature. The reason for this reduction of substrate temperature might be attributed to low gas pressure during deposition, due to the use of a single aperture ion source. The control of film composition by controlling the ion-atom arrival rate ratio achieved the control of work function. It was concluded that the ion beam assisted deposition with microwave ion source provides a possible process of cathode deposition. (C) 2000 American Institute of Physics. [S0034-6748(00)65202-4]
\end{abstract}

\section{INTRODUCTION}

It is well known that the use of ion beam provides thin films with superior property at a lower substrate temperature, especially for compound materials. So far, insulators such as silicon oxide and silicon nitride ${ }^{1}$ and metallic compounds such as transition metal nitrides ${ }^{2}$ have been prepared by ion beam assisted deposition (IBAD). Transition metal nitrides are generally expected as a hard coating material and also as a barrier metal in semiconductor devices, and the intrinsic natures of these materials such as chemical inertness, high melting point, large heat of formation, and high electric conductivity $^{3}$ match the requirement of the cathode material of vacuum microelectronics (VME) devices. Here VME devices are micron-sized vacuum tubes with miniaturized field emission cathode fabricated by contemporary thin film and micromachining technologies. ${ }^{4}$ One of the serious problems of these devices is current fluctuation of emission currents. The emission stability of the bulk nitride cathode is known to be excellent, ${ }^{5}$ but little progress on deposited nitrides can be seen. This is entirely due to the difficulties in synthesis of the nitrides at the lower temperature. As described earlier, thin films of transition metal nitrides have been deposited by IBAD, but substrate temperature as high as $750{ }^{\circ} \mathrm{C}$ is still necessary to obtain the films with an adequately low electrical resistivity. In order to fabricate VME devices on glass substrate for application to flat panel displays, further reduction of the substrate temperature is necessary. We have applied the compact microwave ion source to the deposition of these films through IBAD. ${ }^{6}$ Since previous deposition ${ }^{2}$ was performed under relatively high working pressure, we

\footnotetext{
a) Author to whom correspondence should be addressed; electronic mail: ygotoh@kuee.kyoto-u.ac.jp
}

thought that one of the possible factors to reduce substrate temperature is the lower working pressure. The ion source used in the present study has only one aperture, and the pressure difference could be easily achieved. As a result, we could deposit the polycrystalline zirconium nitride $\left(\mathrm{ZrN}_{x}\right)$ and niobium nitride $\left(\mathrm{NbN}_{x}\right)$ films at a lower substrate temperature. In this article, the film properties of these nitride films estimated from the viewpoint of cold cathode material, are given.

\section{ION BEAM ASSISTED DEPOSITION OF TRANSITION METAL NITRIDES}

\section{A. Deposition system}

Figure 1 shows the schematic diagram of the deposition system. The IBAD system consists of a compact microwave ion source ${ }^{7}$ and electron beam evaporator. To evaporate transition metal which has a relatively high melting point, an electron beam evaporator rather than a resistively heated evaporator is preferred. The ion source utilizes a permanent magnet for the axial magnetic field, and a closed magnetic circuit is formed with ferromagnetic materials. Owing to little leakage of magnetic field, little interference with the electron beam evaporator would be expected. The substrate holder is set above the electron beam evaporator and the ion source is settled at $45^{\circ}$ off with respect to the vertical line. Adjusting the angle of the substrate holder, the ion incident angle was changed, but consequently the incident angle of the depositing metal atoms also changed. It is generally difficult to transport low energy ions effectively due to the space charge effect, thus we adopted an accel-decel type transporting system. The ion source has a single extraction aperture with a diameter of $2 \mathrm{~mm}$. This single aperture enables us to deposit at a lower gas pressure, as described later. 


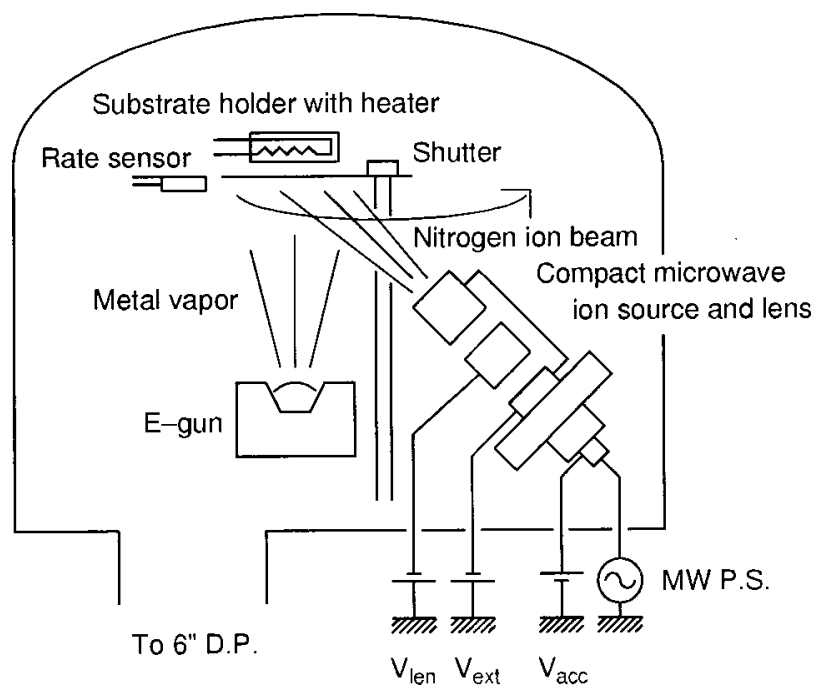

FIG. 1. Schematic diagram of the deposition system.

The ions are extracted once by a high negative potential of several kilovolts. The source possesses an einzel lens and the extracted ion beam can be converged. Deceleration was performed between the end electrode of the einzel lens and substrate holder. In such a system, neutralized ions with higher energy exist. Because these neutralized ions can significantly by damage the films, the substrate holder was located off axis of the ion source. The deposition rate could be monitored by a quartz oscillator. The entire system was pumped by a $6 \mathrm{in}$. oil diffusion pump and the residual gas pressure was about $2 \times 10^{-4} \mathrm{~Pa}$.

\section{B. Deposition condition}

The deposition conditions are summarized in Table I. We have deposited $\mathrm{ZrN}_{x}$ and $\mathrm{NbN}_{x}$ films on a $p$-Si(100) wafer with an ion-atom arrival rate ratio (ARR) and substrate temperature $\left(T_{S}\right)$ as parameters. Here ARR was defined by the atomic flux of nitrogen to that of metal atom flux, assuming that the ion beam is composed of $\mathrm{N}_{2}^{+}$ions. This estimation is based on the experimental evidence that this ion source yields up to $25 \%$ atomic nitrogen ions and a negligible amount of doubly charged atomic ions. ${ }^{7}$ The presence of atomic ions causes an error of up to $20 \%$ in ARR, but the fraction varies with the operating condition; thus we did not take this effect into consideration. For the $\mathrm{ZrN}_{x}$ films, the ion energy and ion incident angle were varied. The nitrogen pressure during deposition was $2 \times 10^{-3} \mathrm{~Pa}$.

TABLE I. Deposition conditions for $\mathrm{ZrN}$ and $\mathrm{NbN}$ films.

\begin{tabular}{lll}
\hline \multicolumn{1}{c}{ Terms } & \multicolumn{1}{c}{$\mathrm{ZrN}$} & \multicolumn{1}{c}{$\mathrm{NbN}$} \\
\hline Evaporation rate & $0.05 \mathrm{~nm} \mathrm{~s}^{-1}$ & $0.03 \mathrm{~nm} \mathrm{~s}^{-1}$ \\
Ion energy & $200 \mathrm{eV}, 500 \mathrm{eV}, 1 \mathrm{keV}$ & $600 \mathrm{eV}$ \\
Ion current density & $6-18 \mu \mathrm{A} \mathrm{cm}{ }^{-2}$ & $11-34 \mu \mathrm{A} \mathrm{cm}{ }^{-2}$ \\
ARR & $0.3-0.9$ & $0.2-2.0$ \\
Substrate temperature & $120-650^{\circ} \mathrm{C}$ & $200-600{ }^{\circ} \mathrm{C}$ \\
Ion incident angle & $45^{\circ}, 22.5^{\circ}$ & $22.5^{\circ}$ \\
\hline \hline
\end{tabular}

\section{FILM PROPERTY}

\section{A. Nitrogen composition}

Nitrogen composition $x$ of the deposited films was estimated by Rutherford backscattering spectrometry (RBS). As for the $\mathrm{NbN}_{x}$ films, $x$ was controlled by controlling ARR. Although the absolute value of the nitrogen composition decreased slightly with an increase of $T_{s}, x$ could be determined by ARR. The typical relation at $T_{s}$ of $500^{\circ} \mathrm{C}$ is: $\mathrm{ARR}=0.3, x=0.3$, and $\mathrm{ARR}=1.8, x=1.1$. For the $\mathrm{ZrN}_{x}$ films, zirconium silicide was formed occasionally, thus the relation between the ARR and $x$ deviated. Nevertheless, $x$ varied in accordance with ARR.

\section{B. Crystallinity}

Crystallinity was evaluated by x-ray diffraction. For both $\mathrm{ZrN}_{x}$ and $\mathrm{NbN}_{x}$, films exhibited amorphous structure when deposited at $T_{s}$ lower than $400{ }^{\circ} \mathrm{C}$. At $T_{s}$ higher than $500{ }^{\circ} \mathrm{C}$, the films tended to be crystallized. For $\mathrm{NbN}_{x}$, the x-ray diffraction pattern showed formation of the different phases of $\mathrm{Nb}_{2} \mathrm{~N}, \mathrm{Nb}_{4} \mathrm{~N}_{3}$, and $\mathrm{NbN}$ in accordance with $x .^{6}$

\section{Electrical resistivity}

Electrical resistivity was measured by a four point probe at room temperature. Figures 2(a) and 2(b) show the relation between $T_{\mathrm{s}}$ and the electrical resistivity for $\mathrm{ZrN}_{x}$ and $\mathrm{NbN}_{x}$ films, respectively. In Fig. 2(a), examples of the temperature dependence of the resistivity reported by Horita et al. $^{2}$ and also by Barnett et al. ${ }^{8}$ are also plotted. The former was performed by ion beam assisted deposition and the latter was performed by magnetron sputtering. As compared with these previous results, we could deposit film with similar resistivity at lower temperature by almost $200{ }^{\circ} \mathrm{C}$. The lowest resistivity obtained in the present study was $25 \mu \Omega \mathrm{cm}$, and very close to bulk value. ${ }^{3}$ The nitrogen pressure during deposition was $10^{-2}$ and $10^{-1} \mathrm{~Pa}$ for the previous cases. The reason why our results showed lower temperature has not been clarified yet, but lower pressure in the deposition chamber may be related to this issue. In fact, deposition with nitrogen introduction around the substrate holder significantly affected the resulting film property, especially electrical resistivity. ${ }^{9}$ Oblique ion incidence of $45^{\circ}$ showed better property. Low ion energy gave lower resistivity at lower $T_{s}$ but the lowest electrical resistivity was obtained with the film deposited by a $1 \mathrm{keV}$ nitrogen beam. For a detailed relation between the instrumental parameters and the film property, further investigation will be necessary.

For $\mathrm{NbN}_{x}$ films, electrical resistivities were higher than the bulk values. At $T_{s}$ of $500{ }^{\circ} \mathrm{C}$, the electrical resistivity of $\mathrm{NbN}$ film was $400-600 \mu \Omega \mathrm{cm}$, and that of $\mathrm{Nb}_{2} \mathrm{~N}$ was 200 $\mu \Omega \mathrm{cm}$.

\section{Electron binding energy}

Atomic bonding was evaluated by $\mathrm{x}$-ray photoelectron spectroscopy (XPS). Prior to measurement, the film surface was cleaned with $3 \mathrm{kV}$ argon ion bombardment. Figure 3 shows a typical example of the $\mathrm{Nb} 3 d$ electron binding energy of $\mathrm{NbN}_{x}$ film deposited with ARR of 1.0. The solid 


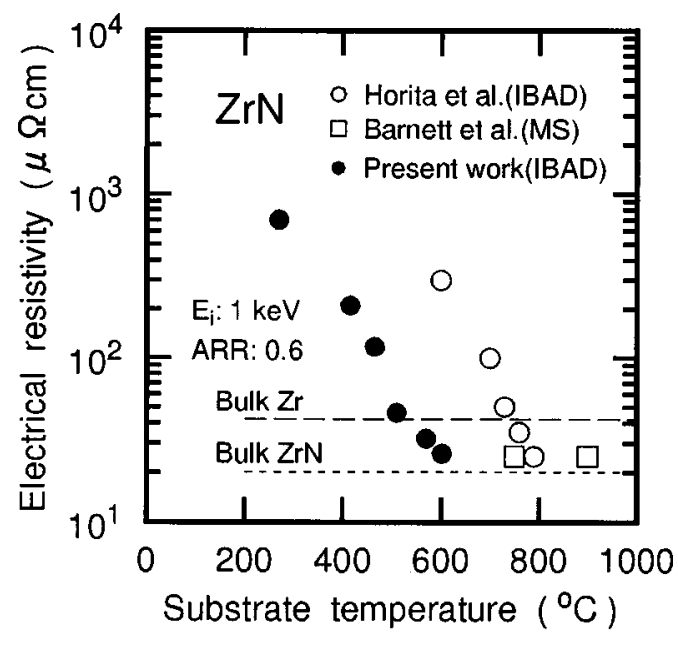

(a)

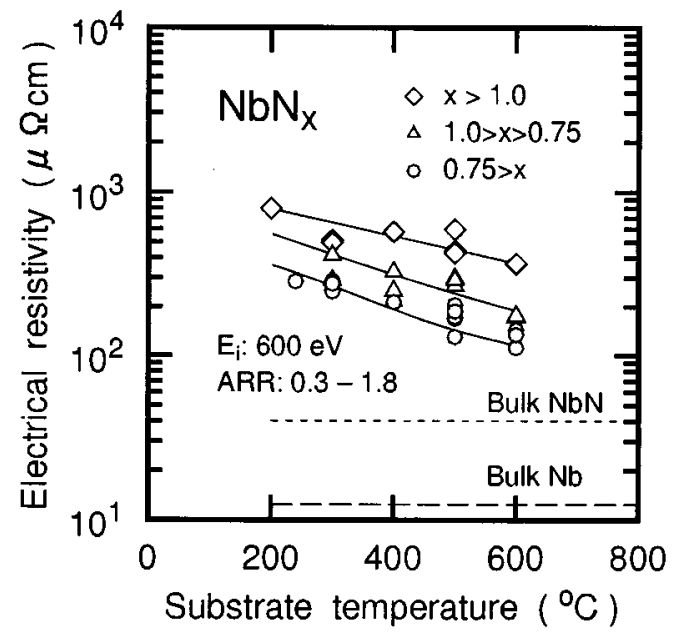

(b)

FIG. 2. Relation between substrate temperature and electrical resistivity: (a) $\mathrm{ZrN}$ films and (b) $\mathrm{NbN}$ films.

vertical line shows the peak position of metallic $\mathrm{Nb} 3 d_{5 / 2}$. A chemical shift to $204.7 \mathrm{eV}$ was seen both for the film deposited with $T_{s}$ of 300 and $600{ }^{\circ} \mathrm{C}$. This result shows nitriding was achieved even at the low $T_{s}$ of $300{ }^{\circ} \mathrm{C}$.

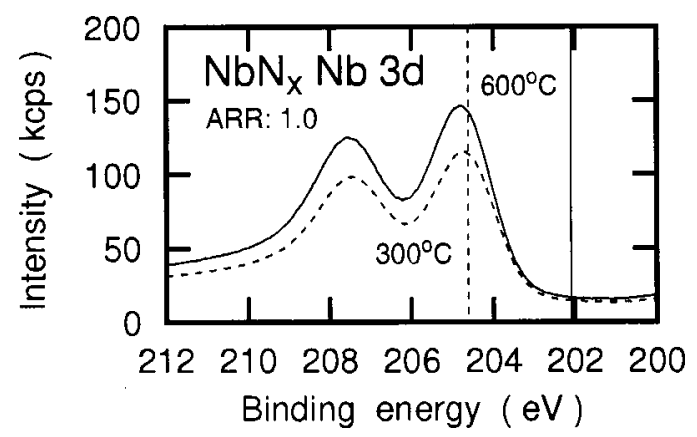

FIG. 3. X-ray photoelectron spectrum of $\mathrm{Nb} 3 d$ electrons of $\mathrm{NbN}$ films.

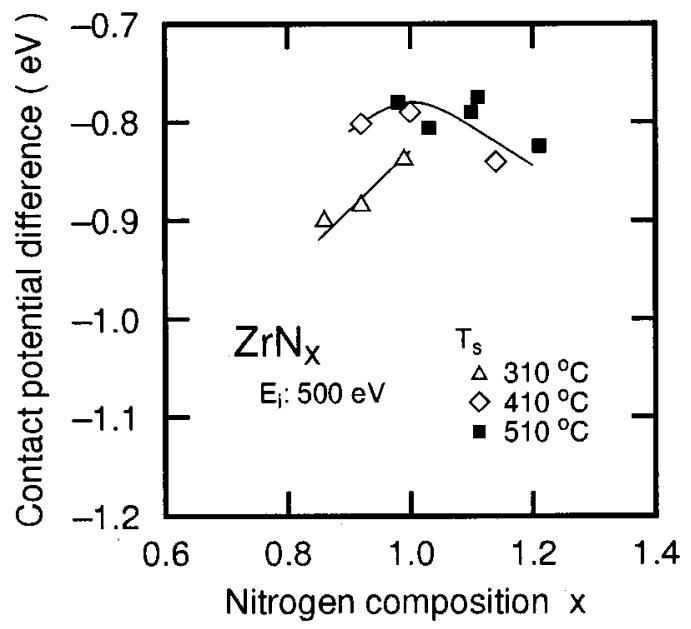

(a)

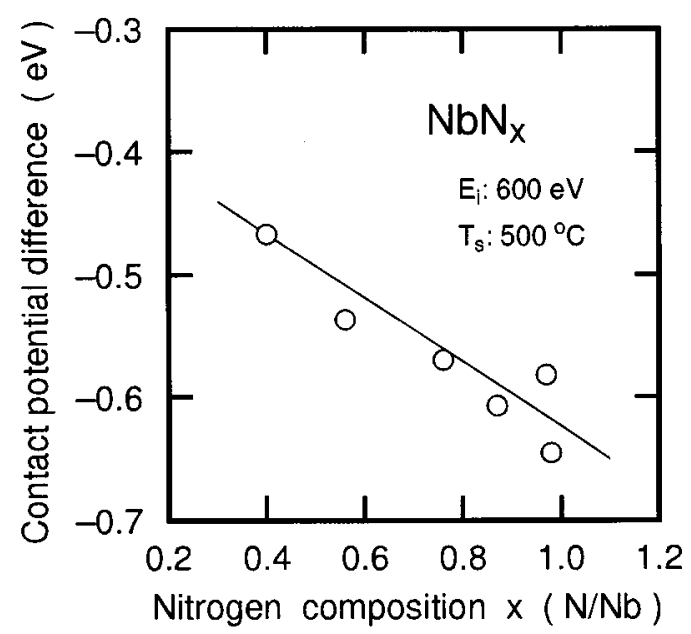

(b)

FIG. 4. Relation between nitrogen composition and work function: (a) $\mathrm{ZrN}$ films and (b) NbN films.

\section{E. Work function}

Work function was evaluated by a Kelvin probe in air. The counter electrode was gold, thus the present result shows a contact potential difference between the sample and gold. The measurement in air does not give a physically meaningful value of work function, but actual VME devices are fabricated through multiple processes including exposure to air and even to acid. In operation, no flushing is generally performed unlike the field emission cathodes for the electron microscope, thus the contaminated surface may give us effective work function in practical operation. Figures 4(a) and 4(b) show the work functions as a function of nitrogen composition $x$, for $\mathrm{ZrN}_{x}$ and $\mathrm{NbN}_{x}$, respectively. For $\mathrm{ZrN}_{x}$, work function increased with an increase in $x$, below $x=1$ and tended to saturate at $x>1$, while for $\mathrm{NbN}_{x}$, work function decreased with an increase in $x$. Bulk $\mathrm{ZrN}$ has higher work function than $\mathrm{Zr}$ and bulk $\mathrm{NbN}$ has slightly lower work 
function than $\mathrm{Nb},{ }^{10}$ thus present results reflect the bulk property.

\section{F. Endurance against low energy ion bombardment}

We have checked the endurance of $\mathrm{NbN}_{x}$ films against $400 \mathrm{eV}$ argon ion bombardment, because cathodes are generally subjected to bombardment of ions which are produced in a space by electron impact. As a result, total sputtering yield of the $\mathrm{Nb}$ film was about 0.4 , and it slightly increased with an increase in the nitrogen composition. Total sputtering yield was about 0.46 for the $\mathrm{NbN}$ film. Taking the fact that sputtering yield of bulk $\mathrm{Nb}$ against $400 \mathrm{eV}$ argon ion bombardment is $0.4,{ }^{11}$ the present values are considered to be low enough.

\section{SUMMARY}

We have applied the compact microwave ion source to the low temperature growth of transition metal nitride thin films for vacuum microelectronics devices. As a result, it was found that polycrystalline films were obtained both for $\mathrm{ZrN}$ and $\mathrm{NbN}$ at a substrate temperature as low as $500^{\circ} \mathrm{C}$. Also the electric resistivity was sufficiently low at this temperature. We could control the work function of these materials, which has significant effect on the field electron emission.

\section{ACKNOWLEDGMENTS}

The authors thank the Staff of the Quantum Science and Engineering Center, Kyoto University, for their assistance in
RBS measurement. XPS measurement was performed as a part of Venture Business Project at Venture Business Laboratory, Kyoto University. The present study was supported by Ministry of Education, Science, Sports, and Culture through Grant-in-Aids for Encouragement of Young Scientists, Nos. 08750036 and 09750016.

${ }^{1}$ H. Takaoka, J. Ishikawa, and T. Takagi, Thin Solid Films 157, 143 (1988).

${ }^{2}$ S. Horita, T. Tujikawa, H. Akahori, M. Kobayashi, and T. Hata, J. Vac. Sci. Technol. A 11, 2452 (1993).

${ }^{3}$ L. E. Toth, Transition Metal Carbides and Nitrides (Academic, New York, 1979), p.1.

${ }^{4}$ See, example the latest proceedings of the International Vacuum Microelectronics Conference appearing in J. Vac. Sci. Technol. B 17, 503 (1999).

${ }^{5}$ M. Endo, H. Nakane, and H. Adachi, J. Vac. Sci. Technol. B 14, 2114 (1996).

${ }^{6}$ Y. Gotoh, M. Nagao, T. Ura, H. Tsuji, and J. Ishikawa, Nucl. Instrum. Methods Phys. Res. B 148, 925 (1999).

${ }^{7}$ J. Ishikawa, Y. Takeiri, and T. Takagi, Rev. Sci. Instrum. 55, 449 (1984).

${ }^{8}$ S. A. Barnett, L. Haltman, J.-E. Sundgren, F. Ronin, and S. Rohde, Appl. Phys. Lett. 53, 400 (1988).

${ }^{9}$ Y. Gotoh, T. Shiigi, M. Nagao, H. Tsuji, and J. Ishikawa, Proceedings of the Ion Implantation Technology IIT'98 (in press).

${ }^{10}$ V. S. Fomenko, Handbook of Electron Emission Property, translated by Nisso Tsushinsha (Nisso Tsusinsha, Wakayama, 1973) (in Japanese).

${ }^{11}$ N. Matsunami, Y. Yamamura, Y. Itikawa, N. Itoh, Y. Kazumata, S. Miyagawa, K. Morita, R. Shimizu, and H. Tawara, Energy Dependence of the Yields of Ion-Induced Sputtering of Monatomic Solids (Institute of Plasma Physics, Nagoya University, 1983). 